\title{
Meta-analysis across Cohorts for Heart and Aging Research in Genomic Epidemiology (CHARGE) consortium provides evidence for an association of serum vitamin $D$ with pulmonary function
}

Jiayi Xu ${ }^{1}$, Traci M. Bartz ${ }^{2,3} \dagger$, Geetha Chittoor ${ }^{4,5} \dagger$, Gudny Eiriksdottir ${ }^{6} \dagger$, Ani W. Manichaikul ${ }^{7} \dagger$, Fangui Sun ${ }^{8} \dagger$, Natalie Terzikhan ${ }^{9,10}$, Xia Zhou ${ }^{11} \dagger$, Sarah L. Booth ${ }^{12}$, Guy G. Brusselle ${ }^{9,10,13}$, Ian H. de Boer ${ }^{14}$, Myriam Fornage ${ }^{15,16}$, Alexis C. Frazier-Wood ${ }^{17}$, Mariaelisa Graff 5 , Vilmundur Gudnason ${ }^{6,18}$, Tamara B. Harris ${ }^{19}$, Albert Hofman ${ }^{10,20,21}$, Ruixue Hou $^{22}$, Denise K. Houston ${ }^{23}$, David R. Jacobs Jr ${ }^{11}$, Stephen B. Kritchevsky ${ }^{23,24,25}$, Jeanne Latourelle ${ }^{26,27}$, Rozenn N. Lemaitre ${ }^{3,14}$, Pamela L. Lutsey ${ }^{11}$, George O'Connor $^{26}$, Elizabeth C. Oelsner ${ }^{28}$, James S. Pankow ${ }^{11}$, Bruce M. Psaty ${ }^{3,14,29,30,31}$, Rebecca R. Rohde ${ }^{5}$, Stephen S. Rich ${ }^{7}$, Jerome I. Rotter ${ }^{32}$, Lewis J. Smith ${ }^{33}$, Bruno H. Stricker ${ }^{10,20}$, V. Saroja Voruganti ${ }^{22}$, Thomas J. Wang ${ }^{34}$, M. Carola Zillikens ${ }^{20,35}$, R. Graham Barr ${ }^{28_{\ddagger}}$, Josée Dupuis ${ }^{8} \ddagger$, Sina A. Gharib ${ }^{14,36} \ddagger$, Lies Lahousse ${ }^{9,10,37} \ddagger$, Stephanie J. London ${ }^{38_{\ddagger}}$, Kari E. North ${ }^{5}$, Albert V. Smith ${ }^{6,18_{\ddagger}}$, Lyn M. Steffen ${ }^{11_{\ddagger}}$, Dana B. Hancock ${ }^{39}$ and Patricia A. Cassano ${ }^{1,40_{*}}$

${ }^{1}$ Division of Nutritional Sciences, Cornell University, Ithaca, NY 14853, USA

${ }^{2}$ Department of Biostatistics, University of Washington, Seattle, WA 98195, USA

${ }^{3}$ Cardiovascular Health Research Unit, University of Washington, Seattle, WA 98101, USA

${ }^{4}$ Department of Biomedical and Translational Informatics, Geisinger, Danville, PA 17822, USA

${ }^{5}$ Department of Epidemiology, Gillings School of Global Public Health, University of North Carolina at Chapel Hill, Chapel Hill, NC 27599, USA

${ }^{6}$ Icelandic Heart Association, Holtasmari 1, 201 Kópavogur, Iceland

${ }^{7}$ Center for Public Health Genomics, University of Virginia School of Medicine, Charlottesville, VA 22903, USA

${ }^{8}$ Department of Biostatistics, Boston University School of Public Health, Boston, MA 02118, USA

${ }^{9}$ Department of Respiratory Medicine, Ghent University Hospital, 9000 Ghent, Belgium

${ }^{10}$ Department of Epidemiology, Erasmus Medical Center, 3000 CA Rotterdam, the Netherlands

${ }^{11}$ Division of Epidemiology and Community Health, University of Minnesota, Minneapolis, MN 55454, USA

${ }^{12}$ Jean Mayer-US Department of Agriculture Human Nutrition Research Center on Aging, Tufts University, Boston, MA O2111, USA

${ }^{13}$ Department of Respiratory Medicine, Erasmus Medical Center, 3015 CE Rotterdam, The Netherlands

${ }^{14}$ Department of Medicine, University of Washington, Seattle, WA 98195, USA

${ }^{15}$ Institute of Molecular Medicine, University of Texas Health Science Center at Houston, Houston, TX 77030, USA

${ }^{16}$ Human Genetics Center, School of Public Health, University of Texas Health Science Center at Houston, Houston, TX 77030, USA

${ }^{17}$ Children's Nutrition Research Center, Baylor College of Medicine, Houston, TX 77030, USA

${ }^{18}$ University of Iceland, Saemundargata 2, 101 Reykjavik, Iceland

${ }^{19}$ Laboratory of Epidemiology, Demography, and Biometry, National Institute on Aging, National Institutes of Health,

Department of Health and Human Services, Bethesda, MD 20892, USA

${ }^{20}$ Netherlands Genomics Initiative (NGI)-sponsored Netherlands Consortium for Healthy Aging, 2333 ZC Leiden, The Netherlands

${ }^{21}$ Department of Epidemiology, Harvard T.H. Chan School of Public Health, Boston, MA 02115, USA

${ }^{22}$ Department of Nutrition and Nutrition Research Institute, University of North Carolina at Chapel Hill, Kannapolis, NC 28081, USA

${ }^{23}$ Sticht Center on Aging, Wake Forest School of Medicine, Winston-Salem, NC 27157, USA

Abbreviations: 1,25-(OH) $)_{2} \mathrm{D}, 1,25$-dihydroxyvitamin D; 25(OH)D, 25-hydroxyvitamin D; AA, African ancestry; AGES, Age, Gene, Environment, Susceptibility Study - Reykjavik, Iceland; ARIC, Atherosclerosis Risk in Communities Study; CARDIA, Coronary Artery Risk Development in Young Adults Study; CHARGE, Cohorts for Heart and Aging Research in Genomic Epidemiology; CHS, Cardiovascular Health Study; COPD, chronic obstructive pulmonary disease; EA, European ancestry; $\mathrm{FEV}_{1}$, forced expiratory volume in the 1st second; FHS (Offspring), Framingham Heart Study -Offspring Cohort; FHS (Gen3), Framingham Heart Study - Generation 3 Cohort; FVC, forced vital capacity; HABC, Health, Aging, and Body Composition Study; MESA, Multi-Ethnic Study of Atherosclerosis; PFT, pulmonary function test; RIA, radioimmunoassay.

*Corresponding author: P. A. Cassano, fax +1 607255 2691, email pac6@cornell.edu

$\dagger$ These authors contributed equally to this work as analysts.

$\ddagger$ These authors contributed equally to this work as principal investigators. 
${ }^{24}$ Section on Gerontology and Geriatric Medicine, Wake Forest School of Medicine, Winston-Salem, NC 27157, USA

${ }^{25}$ Department of Internal Medicine, Wake Forest School of Medicine, Winston-Salem, NC 27157, USA

${ }^{26}$ The Pulmonary Center, Department of Medicine, Boston University, Boston, MA 02118, USA

${ }^{27}$ Department of Neurology, Boston University, Boston, MA 02118, USA

${ }^{28}$ Department of Medicine, Columbia University, New York, NY 10032, USA

${ }^{29}$ Department of Epidemiology, University of Washington, Seattle, WA 98195, USA

${ }^{30}$ Department of Health Services, University of Washington, Seattle, WA 98195, USA

${ }^{31}$ Kaiser Permanente Washington Health Research Institute, Seattle, WA 98101, USA

${ }^{32}$ Institute for Translational Genomics and Population Sciences, Los Angeles Biomedical Research Institute and Department of Pediatrics at Harbor-UCLA Medical Center, Torrance, CA 90502, USA

${ }^{33}$ Division of Pulmonary and Critical Care, Feinberg School of Medicine, Northwestern University, Chicago, IL 60611, USA

${ }^{34}$ Division of Cardiovascular Medicine, Department of Medicine, Vanderbilt University, Nashville, TN 37232, USA

${ }^{35}$ Department of Internal Medicine, Erasmus Medical Center, 3000 CA Rotterdam, The Netherlands

${ }^{36}$ Center for Lung Biology, University of Washington, Seattle, WA 98109, USA

${ }^{37}$ Department of Bioanalysis, Ghent University, 9000 Ghent, Belgium

${ }^{38}$ Division of Intramural Research, National Institute of Environmental Health Sciences, National Institutes of Health, Department of Health and Human Services, Research Triangle Park, NC 27709, USA

${ }^{39}$ Center for Omics Discovery and Epidemiology, Behavioral Health Research Division, RTI International, Research Triangle Park, NC 27709, USA

${ }^{40}$ Department of Healthcare Policy and Research, Division of Biostatistics and Epidemiology, Weill Cornell Medical College, New York, NY 10065, USA

(Submitted 11 March 2018 - Final revision received 2 July 2018 - Accepted 9 July 2018 - First published online 12 September 2018 )

\section{Abstract}

The role that vitamin D plays in pulmonary function remains uncertain. Epidemiological studies reported mixed findings for serum 25-hydroxyvitamin D (25(OH)D)-pulmonary function association. We conducted the largest cross-sectional meta-analysis of the 25(OH)Dpulmonary function association to date, based on nine European ancestry (EA) cohorts ( $n$ 22 838) and five African ancestry (AA) cohorts ( $n$ 4290) in the Cohorts for Heart and Aging Research in Genomic Epidemiology Consortium. Data were analysed using linear models by cohort and ancestry. Effect modification by smoking status (current/former/never) was tested. Results were combined using fixed-effects meta-analysis. Mean serum 25(OH)D was 68 (sD 29) nmol/l for EA and 49 (sD 21) nmol/l for AA. For each $1 \mathrm{nmol} / \mathrm{l} \mathrm{higher} \mathrm{25(OH)D,} \mathrm{forced}$ expiratory volume in the 1 st second $\left(\mathrm{FEV}_{1}\right)$ was higher by $1.1 \mathrm{ml}$ in EA $(95 \% \mathrm{CI} 0 \cdot 9,1 \cdot 3 ; P<0.0001)$ and $1.8 \mathrm{ml}(95 \% \mathrm{CI} 1 \cdot 1,2 \cdot 5 ; P<0 \cdot 0001)$ in AA $\left(P_{\text {race difference }}=0.06\right)$, and forced vital capacity (FVC) was higher by $1.3 \mathrm{ml}$ in EA (95\% CI $\left.1.0,1 \cdot 6 ; P<0.0001\right)$ and $1.5 \mathrm{ml}(95 \% \mathrm{CI} 0.8$, $2 \cdot 3 ; P=0.0001)$ in AA $\left(P_{\text {race difference }}=0.56\right)$. Among EA, the $25(\mathrm{OH}) \mathrm{D}-\mathrm{FVC}$ association was stronger in smokers: per $1 \mathrm{nmol} / 1 \mathrm{higher} 25(\mathrm{OH})$ D, FVC was higher by $1.7 \mathrm{ml}(95 \%$ CI $1 \cdot 1,2 \cdot 3)$ for current smokers and $1.7 \mathrm{ml}(95 \%$ CI $1 \cdot 2,2 \cdot 1)$ for former smokers, compared with $0 \cdot 8 \mathrm{ml}$ $(95 \%$ CI $0 \cdot 4,1 \cdot 2)$ for never smokers. In summary, the $25(\mathrm{OH}) \mathrm{D}$ associations with $\mathrm{FEV}_{1}$ and FVC were positive in both ancestries. In EA, a stronger association was observed for smokers compared with never smokers, which supports the importance of vitamin D in vulnerable populations.

Key words: Vitamin D: Forced expiratory volume: Vital capacity: Respiratory function tests: Smoking: Whites: African Americans

Chronic obstructive pulmonary disease (COPD), the third leading cause of mortality in the $\mathrm{USA}^{(1)}$ and among the top ten leading causes of total years of life lost in the world ${ }^{(2)}$, is characterised by progressive airway obstruction. Pulmonary function tests (PFT), as performed by spirometry, are used to quantify pulmonary function parameters including forced expiratory volume in the 1st second $\left(\mathrm{FEV}_{1}\right)$ and forced vital capacity (FVC). Pulmonary function increases throughout childhood, plateaus in the 20s, and thereafter adults experience an age-related decline ${ }^{(3)}$. The majority of COPD cases $(85 \%)$ are related to smoking ${ }^{(4)}$, which alters the trajectory in pulmonary function, by hindering growth, reducing peak function and accelerating age-related decline ${ }^{(5)}$.

Vitamin $\mathrm{D}$ is proposed to have protective effects in the lungs via gene regulation ${ }^{(6)}$. In vitro studies found that 1,25-dihydroxyvitamin $\mathrm{D}\left(1,25-(\mathrm{OH})_{2} \mathrm{D}\right)$, the active vitamin $\mathrm{D}$ metabolite, induced antimicrobial peptides for host defence in the lung and modulated airway remodelling ${ }^{(7)}$. In humans, 25hydroxyvitamin D (25(OH)D) is the major vitamin D metabolite in serum, most of which forms a complex with vitamin D binding protein (DBP) (approximately $85-90 \%$ is DBPbound $)^{(8)}$, and then is metabolised to $1,25-(\mathrm{OH})_{2} \mathrm{D}$, the active steroid hormone form ${ }^{(8,9)}$. Total $25(\mathrm{OH}) \mathrm{D}$ is the commonly used biomarker of vitamin D status, and it is preferred to other vitamin D metabolites, such as non-DBP-bound 25(OH)D and $1,25-(\mathrm{OH})_{2} \mathrm{D}$, given that it is a comprehensive indicator for vitamin D stores, has a longer half-life (approximately 3 weeks) and is less affected by $\mathrm{Ca}^{(10,11)}$. On average, African ancestry (AA) populations have lower serum 25(OH)D concentrations, 
due to multiple factors including genetics and skin pigmentation $^{(7)}$, but evidence exists that AA populations have higher $1,25-(\mathrm{OH})_{2} \mathrm{D}$ levels and greater bone mineral density compared with European ancestry (EA) populations ${ }^{(12)}$.

Previous observational cross-sectional studies of the vitamin Dpulmonary function association in the general population reported mixed findings. Most of these studies reported a positive association between $25(\mathrm{OH}) \mathrm{D}$ and pulmonary function ${ }^{(13-19)}$, although some reported a null or inverse association ${ }^{(20-22)}$, and two others reported a positive association under certain conditions, such as only in male current smokers ${ }^{(23)}$ or only in overweight and obese males $^{(24)}$. The largest previous cross-sectional study, which included two Danish cohorts (total 18507), reported positive associations of $25(\mathrm{OH}) \mathrm{D}$ with pulmonary function ${ }^{(16)}$. Only one prior cross-sectional study investigated serum $25(\mathrm{OH}) \mathrm{D}$ and pulmonary function in an ancestry group other than European, and it confirmed similar positive associations in the 3957 AA participants studied $^{(13)}$.

The current study investigated the hypothesis that serum $25(\mathrm{OH}) \mathrm{D}$ level is positively associated with pulmonary function. We leveraged the Cohorts for Heart and Aging Research in Genomic Epidemiology (CHARGE) Consortium to include population-based data on serum $25(\mathrm{OH}) \mathrm{D}$ and pulmonary function in a harmonised analysis. In addition, we compared the association of serum $25(\mathrm{OH}) \mathrm{D}$ and pulmonary function across EA and AA groups and investigated effect modification by cigarette smoking.

\section{Methods}

\section{Cohorts and participants}

Nine prospective cohorts in the CHARGE Consortium were included (Table 1). All cohorts had EA participants, and five of the cohorts had AA participants. Only one cohort (Multi-Ethnic Study of Atherosclerosis (MESA)) has participants with other ancestries, and these other ancestries were not included in this study. Among the nine cohorts, the Framingham Heart Study (FHS) had two sub-cohorts analysed separately: the Offspring and the Third-Generation (Gen3) cohorts. Our analysis pipeline harmonised the outcome and exposure definitions, the units on all variables and the statistical modelling. The same exclusion criteria were applied to each cohort: missing PFT, unacceptable PFT using the American Thoracic Society and European Respiratory Society criteria for acceptability, missing serum $25(\mathrm{OH}) \mathrm{D}$, serum $25(\mathrm{OH}) \mathrm{D}>374.4 \mathrm{nmol} / \mathrm{l}$ (or $150 \mathrm{ng} / \mathrm{ml}$, leading to removal of a single outlier) $)^{(25)}$ or missing on other covariates (online Supplementary Table S1).

\section{Outcome and exposure assessment}

Pre-bronchodilator pulmonary function outcomes $\left(\mathrm{FEV}_{1}, \mathrm{FVC}\right.$ and $\mathrm{FEV}_{1} / \mathrm{FVC}$ ), which have similar accuracy as postbronchodilator measures for long-term outcomes ${ }^{(26)}$, were measured in each cohort using standardised methods defined by the American Thoracic Society/European Respiratory Society criteria (online Supplementary Table S2). The methods used to measure $25(\mathrm{OH}) \mathrm{D}$ varied by cohort (online Supplementary
Table S2). Three cohorts, including MESA, the Atherosclerosis Risk In Communities (ARIC) study, and the Cardiovascular Health Study (CHS), used the current reference method, liquid chromatography in tandem with mass spectrometry (LC-MS/ MS); three cohorts, including FHS, the Coronary Artery Risk Development in Young Adults (CARDIA) study, and the Health, Aging, and Body Composition (HABC) study, used radioimmunoassay (RIA); one cohort, the Age, Gene, Environment, Susceptibility Study - Reykjavik, Iceland (AGES), used chemiluminescence immunoassay (CLIA); and one cohort (the Rotterdam Study (RS)) used electro-CLIA. Only MESA calibrated the serum 25(OH)D measurement against the standard reference material $972^{(27)}$, which reflects the calendar time of the measurements in the cohorts, most of which occurred before the availability of the standard reference material (online Supplementary Table S3). Measurements of the outcome and exposure variables were planned for either the full cohort (ARIC, CHS, FHS, HABC and RS) or a subset of the cohort if the outcome or the exposure was only measured in an ancillary study (AGES, CARDIA and MESA) ${ }^{(28-31)}$ (online Supplementary Table S1). Continuous variables were used for serum $25(\mathrm{OH}) \mathrm{D}$ and pulmonary function to capture the association of $25(\mathrm{OH}) \mathrm{D}$ on PFT across the broad distribution of ranges in the cohorts.

As shown in Table 1, among nine cohorts, four (AGES, CHS, FHS-Offspring and FHS-Gen3) had a mean time difference of $<1$ year in the PFT measurements and the preceding $25(\mathrm{OH}) \mathrm{D}$ measurement, and the greatest mean time difference between $25(\mathrm{OH}) \mathrm{D}$ and PFT measurement was $<5$ years (MESA). Participants in ARIC and HABC had blood drawn for serum 25(OH)D after their PFT measure, but within 3 years.

Other covariates, including smoking status, pack-years (number of packs of cigarettes smoked per $d$ times the number of years smoked), height, weight and age, were measured concurrently with pulmonary function, except for CHS, which assessed covariates concurrent with the serum 25(OH)D measure, but within 1 year of the PFT measurement (online Supplementary Table S3). All data collection and analysis was approved by the Institutional Review Board at each cohort's respective institution. Spirometry measures are available on the database of Genotypes and Phenotypes via accession numbers as follows: ARIC (phs000280), CARDIA (phs000285), CHS (phs000287), FHS (phs000007) and MESA (phs000209). Serum vitamin D measures are also available at the same accession numbers for CHS, FHS and MESA.

\section{Statistical analysis in individual cohorts}

All analyses were first conducted independently in each cohort, stratified by ancestry, given the lower mean serum $25(\mathrm{OH}) \mathrm{D}$ level in AA participants ${ }^{(7)}$. For $\mathrm{FEV}_{1}$ and $\mathrm{FEV}_{1} / \mathrm{FVC}$, models were adjusted for smoking status, pack-years, height, height squared, age, age squared, sex, season of blood draw and study centre (if applicable); for FVC, the model was further adjusted for weight. Residual outliers, identified using the studentised residuals of the linear models (online Supplementary methods for more details), were excluded from all models (about $0 \cdot 3 \%$ of the total sample size). The model was extended to test the 
interaction between 25(OH)D and smoking status (never (reference group), former and current smokers).

\section{Meta-analysis}

We tested the association of serum 25(OH)D on each PFT outcome among individuals in each ancestry group and each cohort, separately, and then combined the effect estimates (also referred to as two-stage meta-analysis ${ }^{(32)}$ ), using inverse variance weighting and assuming fixed-effects, with heterogeneity assessed via the $I^{2}$ statistic $^{(33)}$. Random-effects meta-analysis was performed as a sensitivity analysis if there was potential heterogeneity $\left(I^{2}>30 \%\right)$. The comparison of meta-analysed coefficients of the 25(OH)D-PFT associations for the two ancestry groups was conducted using a $Z$ test $^{(34)}$. Meta-analysis of the interaction terms of $25(\mathrm{OH}) \mathrm{D}$ with smoking status was also performed (online Supplementary methods for more details, online Supplementary Tables S4 and S5 for cohortspecific findings and online Supplementary Table S6 for metaanalysed results).

Meta-regression was conducted to explore the potential causes of moderate heterogeneity in the meta-analysis of 25(OH)D on $\mathrm{FEV}_{1}$ and FVC in the EA cohorts. Modifiers were tested individually in the meta-regression models to investigate heterogeneity; modifiers included factors that could vary between cohorts, such as proportion of ever, current and former smokers, mean $25(\mathrm{OH}) \mathrm{D}$ level, assay method for serum $25(\mathrm{OH}) \mathrm{D}$, time between $25(\mathrm{OH}) \mathrm{D}$ and PFT measures, and mean age of participants in each cohort. The two-sided type I error was examined at 0.05 for all analyses. Meta-analysis and meta-regression were conducted using the metafor package (version 1.9-8) in R (version 3.2.3.; R Foundation for Statistical Computing).

Regression coefficients $(\beta)$ with their standard errors calculated within each cohort per $1 \mathrm{nmol} / 125(\mathrm{OH}) \mathrm{D}$ are presented in the figures. In addition, to put the magnitude of the $25(\mathrm{OH}) \mathrm{D}$ PFT associations in terms relevant to public health, the metaanalysed regression coefficients were multiplied by $10 \mathrm{nmol} / \mathrm{l}$ $25(\mathrm{OH}) \mathrm{D}$, which is about half of the standard deviation of the $25(\mathrm{OH}) \mathrm{D}$ distribution.

\section{Results}

We studied 22838 EA and 4290 AA participants. EA participants had higher $\mathrm{FEV}_{1}, \mathrm{FVC}$ and serum 25(OH)D than AA participants in each cohort, whereas $\mathrm{FEV}_{1} / \mathrm{FVC}$ was similar across ancestry groups (Table 1 and online Supplementary Fig. S1). CARDIA and FHS-Gen3 were younger than the seven other cohorts, with consequently lower pack-years smoked in ever smokers. Across all cohorts, among EA participants, $17 \%$ were current smokers and $40 \%$ were former smokers; among AA participants, 22\% were current smokers and 30\% were former smokers. The mean serum $25(\mathrm{OH}) \mathrm{D}$ level was highest among never smokers (70 ( $\mathrm{sD} 30) \mathrm{nmol} / \mathrm{l}$ ), followed by former smokers (67 (sD 29) nmol/l) and current smokers (64 (29) nmol/l) in EAs, whereas the trend was less obvious in AA (49 (sD 21) nmol/l in current smokers, 50 (sD 21) nmol/1 in former smokers and 48 (SD 21) nmol/l in never smokers). The mean of serum $25(\mathrm{OH}) \mathrm{D}$ for EA participants across nine cohorts was 68 (SD 29) nmol/l and for AA participants across five cohorts the mean was 49 (SD 21) nmol/l.

Fixed-effects meta-analysis (Fig. 1) revealed a consistently positive association of serum 25(OH)D with the PFT outcomes, $\mathrm{FEV}_{1}$ and $\mathrm{FVC}$, in both ancestry groups. To put these findings into context, a $10 \mathrm{nmol} / 1$ (approximately $0.5 \mathrm{sD}$ ) higher $25(\mathrm{OH})$ $\mathrm{D}$ was associated with $11.1 \mathrm{ml}$ higher $\mathrm{FEV}_{1}$ in EA $(P<0.0001)$ and $17.9 \mathrm{ml}$ higher $\mathrm{FEV}_{1}$ in $\mathrm{AA}(P<0.0001)$. Similarly, for a $10 \mathrm{nmol} / 1$ higher $25(\mathrm{OH}) \mathrm{D}, \mathrm{FVC}$ was higher by $12.9 \mathrm{ml}$ in EA $(P<0.0001)$ and by $15.4 \mathrm{ml}$ in AA $(P=0.0001)$. The magnitudes of the 25(OH)D-PFT associations did not differ significantly between the two ancestry groups $(P=0.06$ and $P=0.56$ for $\mathrm{FEV}_{1}$ and FVC, respectively). The association of serum $25(\mathrm{OH}) \mathrm{D}$ with $\mathrm{FEV}_{1} / \mathrm{FVC}$ reached statistical significance only in EA $(P=0.0013)$, and the magnitude was negligible; a $10 \mathrm{nmol} / \mathrm{l}$ higher $25(\mathrm{OH}) \mathrm{D}$ was associated with a ratio being lower by 0.055\% (online Supplementary Table S7 and Supplementary Fig. S2 for ancestry- and cohort-specific findings).

In the main-effect meta-analysis of serum 25(OH)D on pulmonary function, EA cohorts had low to moderate heterogeneity, whereas AA cohorts had low heterogeneity (Fig. 1, online Supplementary Fig. S2). We did a sensitivity analysis using random-effects meta-analysis among EA cohorts for the $\mathrm{FEV}_{1}$ and $\mathrm{FVC}$ outcomes, and no substantial change was found in the meta-analysed effect estimates and corresponding SE (coefficient of $1 \mathrm{nmol} / 125(\mathrm{OH}) \mathrm{D}$ on the $\mathrm{FEV}_{1}$ outcome was $1 \cdot 11$ (sE 0.12) $\mathrm{ml}$ in the fixed-effects model and 1.21 (sE 0.19) $\mathrm{ml}$ in the random-effects model; coefficient on the FVC outcome was 1.29 (sE $0 \cdot 14) \mathrm{ml}$ in the fixed-effects model and 1.31 (sE 0.20) $\mathrm{ml}$ in the random-effects model). Meta-regression was also performed in the EA cohorts and we found that among these cohorts, cohorts with lower mean $25(\mathrm{OH}) \mathrm{D}$ concentration had stronger 25(OH)D-PFT associations (Fig. 2). The proportion of ever smokers and of former smokers had significant linear associations with the 25(OH)D-PFT coefficients (online Supplementary Fig. S3), and these two variables were both highly correlated with mean 25(OH)D levels (Pearson's $r<-0.75$ for all pairwise correlations). The $25(\mathrm{OH}) \mathrm{D}-\mathrm{PFT}$ association in EA cohorts varied by $25(\mathrm{OH}) \mathrm{D}$ assay method (meta-regression $P=0.0059)$; the association was attenuated in cohorts using RIA compared with cohorts using liquid chromatography in tandem with MS (pairwise $P<0 \cdot 005$, online Supplementary Fig. S4). Mean age of each cohort was a significant positive modifier of the 25 $(\mathrm{OH}) \mathrm{D}-\mathrm{FEV}_{1}$ association, while time difference between $25(\mathrm{OH}) \mathrm{D}$ and spirometry measures did not affect the $25(\mathrm{OH}) \mathrm{D}-\mathrm{PFT}$ association (online Supplementary Fig. S3).

To examine the potential impact of family relatedness between the FHS-Gen3 and the FHS-Offspring cohorts on the meta-analysis, sensitivity analysis confirmed that the findings were unchanged when either cohort was excluded (results not shown). In addition, the meta-analysis findings were not sensitive to exclusion of residual outliers.

In the EA cohorts, $25(\mathrm{OH}) \mathrm{D}$ had a greater positive association with FVC in current smokers than in never smokers $\left(\beta_{\text {current } \times 25(\mathrm{OH}) \mathrm{D}}=\right.$ $7.5 \mathrm{ml}$ for $10 \mathrm{nmol} / 1$ increment of $25(\mathrm{OH}) \mathrm{D}, \quad P=0.047)$. Similarly, 25(OH)D had a greater positive association with FVC 


\section{NS British Journal of Nutrition}

Table 1. Cross-sectional participant characteristics of each cohort in the Cohorts for Heart and Aging Research in Genomic Epidemiology Consortium ( $n 27$ 128) ${ }^{\star}$ (Mean values and standard deviations)

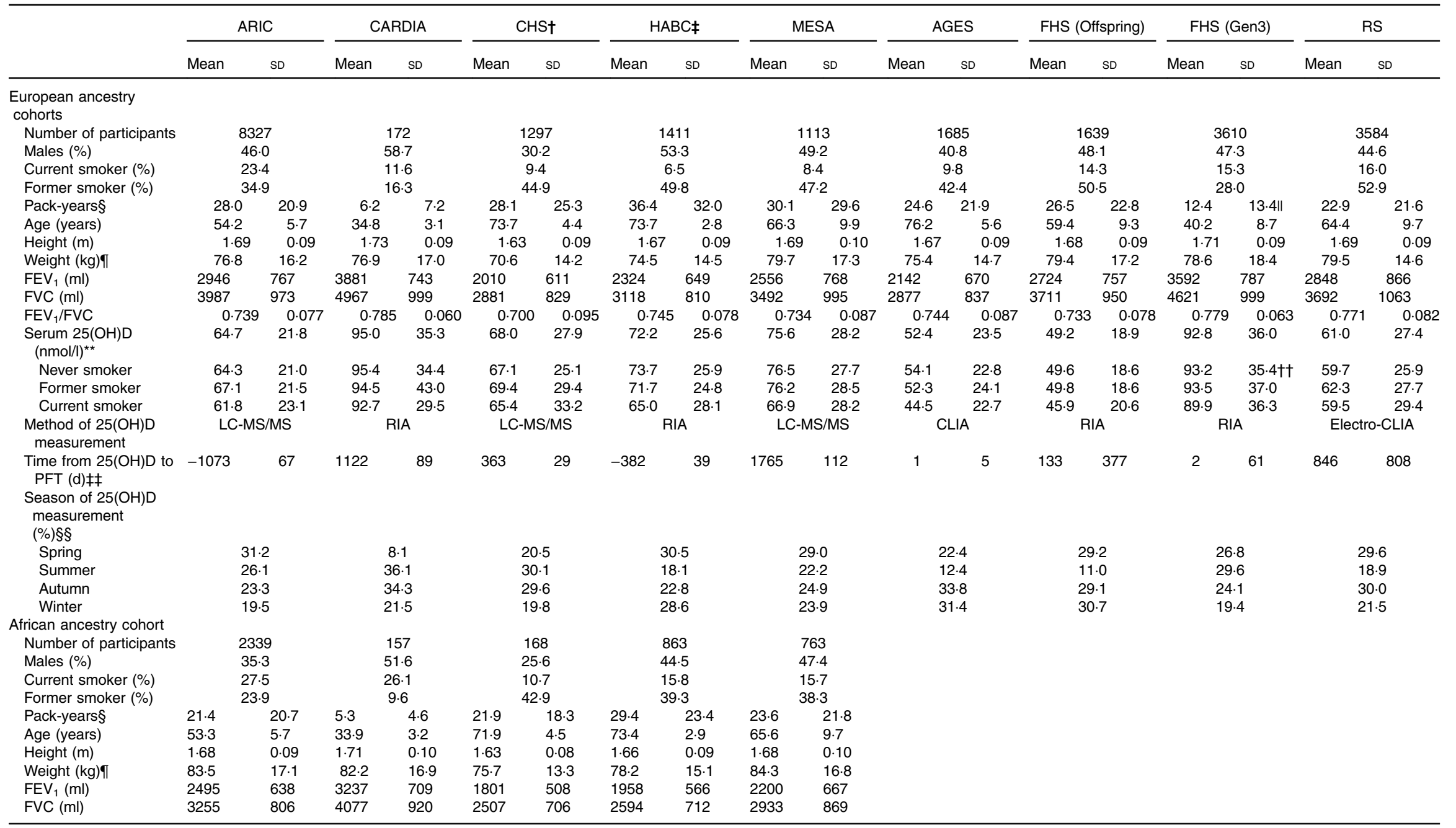




\section{N British Journal of Nutrition}

\begin{tabular}{|c|c|c|c|c|c|c|c|c|c|c|c|c|c|c|c|c|c|c|}
\hline & \multicolumn{2}{|c|}{ ARIC } & \multicolumn{2}{|c|}{ CARDIA } & \multicolumn{2}{|c|}{ CHSt } & \multicolumn{2}{|c|}{ HABC‡ } & \multicolumn{2}{|c|}{ MESA } & \multicolumn{2}{|c|}{ AGES } & \multicolumn{2}{|c|}{ FHS (Offspring) } & \multicolumn{2}{|c|}{ FHS (Gen3) } & \multicolumn{2}{|c|}{ RS } \\
\hline & Mean & SD & Mean & SD & Mean & SD & Mean & SD & Mean & $\mathrm{SD}$ & Mean & SD & Mean & SD & Mean & SD & Mean & SD \\
\hline $\mathrm{FEV}_{1} / \mathrm{FVC}$ & 0.768 & 0.077 & 0.799 & 0.070 & 0.723 & 0.076 & 0.757 & 0.090 & 0.755 & 0.093 & & & & & & & & \\
\hline $\begin{array}{l}\text { Serum } 25(\mathrm{OH}) \mathrm{D} \\
(\mathrm{nmol} /)^{\star *}\end{array}$ & $47 \cdot 4$ & 17.5 & 69.4 & 31.2 & 44.6 & $21 \cdot 1$ & 51.8 & $22 \cdot 4$ & 47.9 & $22 \cdot 3$ & & & & & & & & \\
\hline Never smoker & $46 \cdot 8$ & $16 \cdot 7$ & 71.3 & $30 \cdot 1$ & 43.7 & $19 \cdot 2$ & $51 \cdot 8$ & $22 \cdot 7$ & 49.1 & $22 \cdot 3$ & & & & & & & & \\
\hline Former smoker & 48.5 & 18.0 & 69.2 & 35.6 & $47 \cdot 2$ & $24 \cdot 2$ & $52 \cdot 3$ & $21 \cdot 8$ & 49.3 & 22.6 & & & & & & & & \\
\hline Current smoker & 47.5 & 18.4 & 64.8 & 32.4 & 38.3 & 14.9 & 50.4 & $23 \cdot 2$ & $40 \cdot 9$ & 20.0 & & & & & & & & \\
\hline $\begin{array}{l}\text { Method of 25(OH)D } \\
\text { measurement }\end{array}$ & \multicolumn{2}{|c|}{ LC-MS/MS } & \multicolumn{2}{|c|}{ RIA } & \multicolumn{2}{|c|}{ LC-MS/MS } & \multicolumn{2}{|c|}{ RIA } & \multicolumn{2}{|c|}{ LC-MS/MS } & & & & & & & & \\
\hline \multicolumn{19}{|l|}{$\begin{array}{l}\text { Season of 25(OH)D } \\
\text { measurement } \\
(\%) \S \S\end{array}$} \\
\hline Spring & \multirow{2}{*}{\multicolumn{2}{|c|}{$\begin{array}{l}30.0 \\
30.7\end{array}$}} & \multirow{2}{*}{\multicolumn{2}{|c|}{$\begin{array}{l}10 \cdot 2 \\
56 \cdot 0\end{array}$}} & \multicolumn{2}{|c|}{58.9} & \multicolumn{2}{|c|}{$35 \cdot 6$} & \multicolumn{2}{|c|}{34.6} & & & & & & & & \\
\hline Summer & & & & & \multirow{2}{*}{\multicolumn{2}{|c|}{$\begin{array}{l}7 \cdot 1 \\
8.9\end{array}$}} & \multirow{2}{*}{\multicolumn{2}{|c|}{$\begin{array}{l}16 \cdot 2 \\
24.9\end{array}$}} & \multirow{2}{*}{\multicolumn{2}{|c|}{$23 \cdot 5$}} & & & & & & & & \\
\hline Autumn & \multirow{2}{*}{\multicolumn{2}{|c|}{$20 \cdot 7$}} & \multicolumn{2}{|c|}{$23 \cdot 6$} & & & & & & & & & & & & & & \\
\hline Winter & & 18.6 & \multicolumn{2}{|c|}{10.2} & \multicolumn{2}{|c|}{$25 \cdot 0$} & \multicolumn{2}{|c|}{23.3} & \multicolumn{2}{|c|}{22.3} & & & & & & & & \\
\hline
\end{tabular}

ARIC, Atherosclerosis Risk in Communities Study; CARDIA, Coronary Artery Risk Development in Young Adults Study; CHS, Cardiovascular Health Study; HABC, Health, Aging, and Body Composition Study; MESA, Multi-Ethnic Study of Atherosclerosis; AGES, Age, Gene, Environment, Susceptibility Study - Reykjavik, Iceland; FHS (Offspring), Framingham Heart Study - Offspring Cohort; FHS (Gen3), Framingham Heart Study - Generation 3 Cohort; RS, Rotterdam Study (Netherlands); $\mathrm{FEV}_{1}$, forced expiratory volume in the 1st second; FVC, forced vital capacity; 25(OH)D, 25-hydroxyvitamin D; LC-MS/MS, liquid chromatography in tandem with MS; CLIA, chemiluminescence immunoassay; RIA, radioimmunoassay.

*AGES, RS and FHS only have participants of European ancestry; $n 22838$ for EA, $n 4290$ for AA, total $n 27128$.

† The number of participants used to compute descriptive statistics in CHS excluded those who had residual outliers based on the preliminary models ( $n 8$ for EA and $n 6$ for AA); whereas other cohorts used the number of participants before applying residual exclusion tor the descriptive statistics.

$\neq$ Numbers vary slightly for different outcomes in HABC (for the FVC outcome, $n 1385$ for EA and $n 821$ for AA; for the ratio outcome, $n 1382$ for EAs and $n 817$ for AAs). The numbers of participants for the FEV 1 outcome are used. However the descriptive stalistics is simlar across dimerent outcomes.

in each cohort.

We

II The number of participants who have weight data is slightly different from the total number of participants in each cohort. However, the descriptive statistics of weight stays similar.

Mean (SD) of serum 25(OH)D level for all the participants in each cohort, and mean (sD) of 25(OH)D level in participants with each smoking status are shown here, stratified by ancestry.

t† We used 2049 never smokers in the Gen3 cohort, to compute the 25(OH)D level in never smokers.

玤 was measured after the pulmonary function test.

$\S \S$ The proportion of participants in each season when their serum was measured was rounded (thus rounding errors mean sums may not be exactly $100 \%$ ). 
(a)

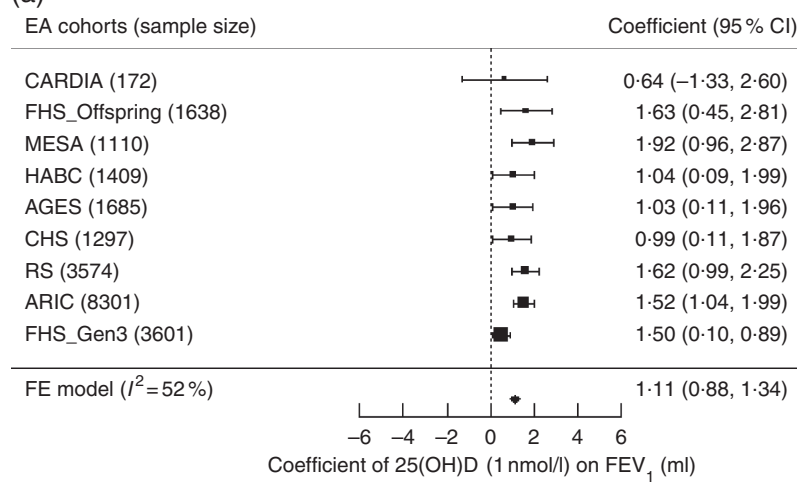

(c)

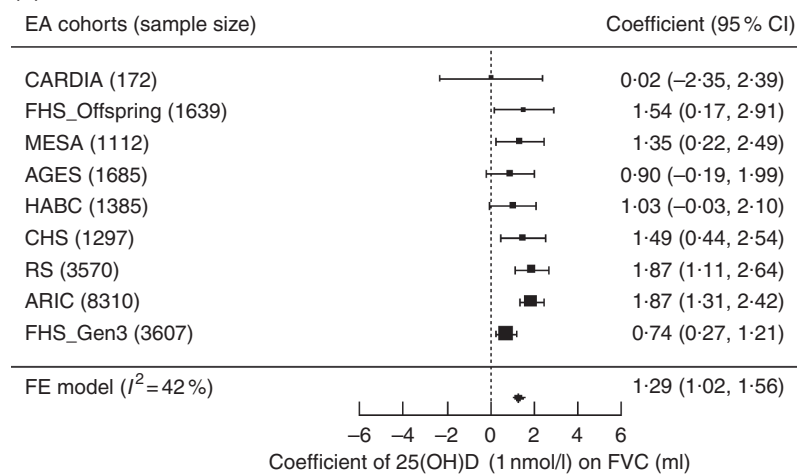

(b)

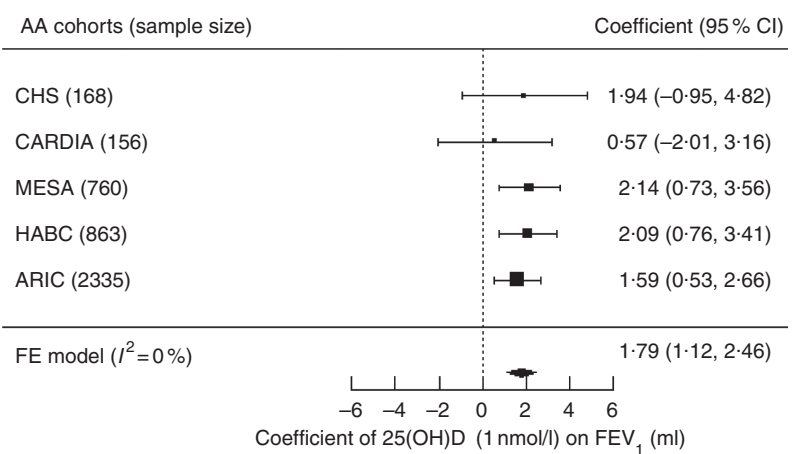

(d)

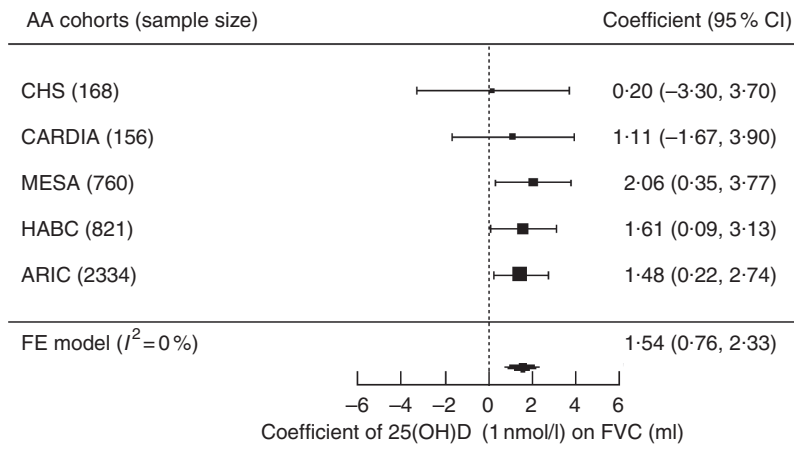

Fig. 1. Forest plots of the meta-analysis of serum 25 -hydroxyvitamin $D(25(\mathrm{OH}) \mathrm{D})$ on forced expiratory volume in the 1 st second $\left(\mathrm{FEV}_{1}\right)$ and forced vital capacity (FVC) across cohorts in the Cohorts for Heart and Aging Research in Genomic Epidemiology Consortium, stratified by participant ancestry. Associations are

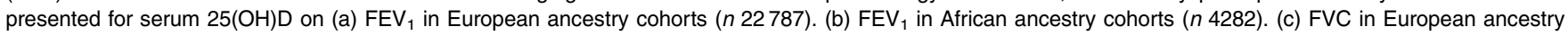
cohorts $(n$ 22 777). (d) FVC in African ancestry cohorts $(n 4239)$. $\beta$ (unit: $\mathrm{ml}$ ) denotes the coefficient from the fixed-effects meta-analysis for serum $25(\mathrm{OH}) \mathrm{D}$ on the pulmonary function outcome per $1 \mathrm{nmol} / \mathrm{lincrement}$ of $25(\mathrm{OH}) \mathrm{D}$, with its $95 \% \mathrm{Cl}$. Cohorts findings were ordered from the least to the most precise, and heterogeneity is presented $(R)$. EA, European ancestry; AA, African ancestry; CARDIA, Coronary Artery Risk Development in Young Adults Study; FHS (Offspring), Framingham Heart Study - Offspring Cohort; AGES, Age, Gene, Environment, Susceptibility Study - Reykjavik, Iceland; CHS, Cardiovascular Health Study; RS, Rotterdam Study (Netherlands); ARIC, Atherosclerosis Risk in Communities Study; FHS (Gen3), Framingham Heart Study - Generation 3 Cohort; FE, fixed-effects; HABC, Health, Aging, and Body Composition Study; MESA, Multi-Ethnic Study of Atherosclerosis.

in former smokers than in never smokers $\left(\beta_{\text {former } \times 25(\mathrm{OH}) \mathrm{D}}=7.9 \mathrm{ml}\right.$ for $10 \mathrm{nmol} / \mathrm{l}$ increment of $25(\mathrm{OH}) \mathrm{D}, P=0.0065$ ) (Fig. 3). For the $\mathrm{FEV}_{1}$ outcome in the EA cohorts, the interaction coefficients for 25 $(\mathrm{OH}) \mathrm{D}$ and smoking status had the same positive direction as the coefficients for FVC, but were not statistically significant for either current $(P=0 \cdot 14)$ or former smokers $(P=0 \cdot 14)$. No statistical evidence of interaction of $25(\mathrm{OH}) \mathrm{D}$ and cigarette smoking was found in the AA cohorts for either outcome. To put the interaction finding into context, a $10 \mathrm{nmol} / \mathrm{L}$ higher serum 25(OH)D was associated with a $17.3 \mathrm{ml}$ higher FVC in current smokers and a $16.6 \mathrm{ml}$ higher FVC in former smokers, which was more than double the association magnitude in never smokers $(\beta=7.8 \mathrm{ml})$. A similar trend was found for the $\mathrm{FEV}_{1}$ outcome in the EA cohorts. For $10 \mathrm{nmol} / \mathrm{l}$ higher serum 25(OH)D, $\mathrm{FEV}_{1}$ was higher by $14.0 \mathrm{ml}$ in current smokers, $12.0 \mathrm{ml}$ in former smokers and $8.0 \mathrm{ml}$ in never smokers (Fig. 4).

\section{Discussion}

This study investigated the association of serum 25(OH)D with pulmonary function using multiple cohorts of different ancestries. We found a consistently positive association of serum 25
$(\mathrm{OH}) \mathrm{D}$ with $\mathrm{FEV}_{1}$ and FVC across both EA and AA groups. In addition, in the EA group, a significantly stronger association was observed for current and former smokers, compared with never smokers.

A previous cross-sectional study in a EA population (two Copenhagen cohorts: $n 10116$ and $n$ 8391, respectively) similarly reported positive associations of $25(\mathrm{OH}) \mathrm{D}$ with $\mathrm{FEV}_{1}$ percentage predicted and FVC percentage predicted, but not with $\mathrm{FEV}_{1} / \mathrm{FVC}^{(16)}$. The magnitude of the association was about four times greater in the Copenhagen study, which may be due to the difference in the mean serum 25(OH)D (Danish median approximately $42 \mathrm{nmol} / 1 v$. CHARGE median of approximately $65 \mathrm{nmol} / \mathrm{l})$ given our finding that the $25(\mathrm{OH}) \mathrm{D}-\mathrm{PFT}$ association was stronger in cohorts with lower serum 25(OH)D. Our finding for the serum $25(\mathrm{OH}) \mathrm{D}-\mathrm{FEV}_{1}$ association was similar in magnitude to the association reported in a British cohort of 6789 participants with an average age of 45 years ${ }^{(17)}$, but weaker than a previous report from the FHS cohort ${ }^{(15)}$. Given that the rate of decline in $\mathrm{FEV}_{1}$ at age 45 years is increased by approximately $15 \mathrm{ml} /$ year in current smokers ${ }^{(35)}$, we estimate that a $10 \mathrm{nmol} / 1$ higher $25(\mathrm{OH}) \mathrm{D}$ is similar to approximately 1 year of current smoking-related decline in $\mathrm{FEV}_{1}$ for both ancestries, but in the opposite direction. Several putative 
(a)

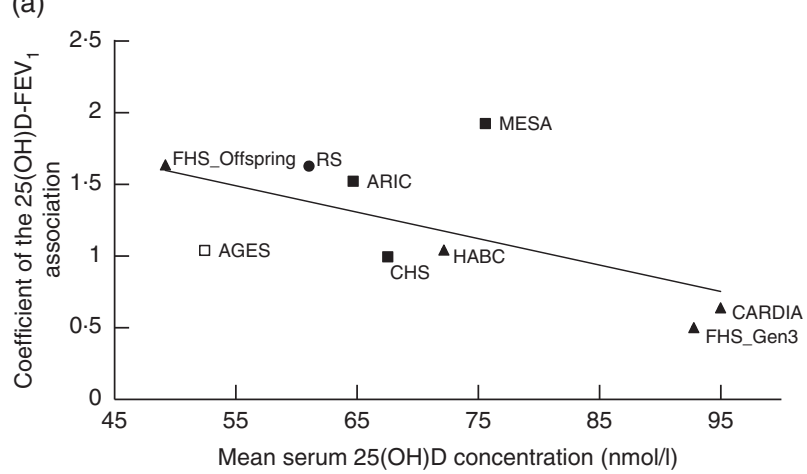

(b)

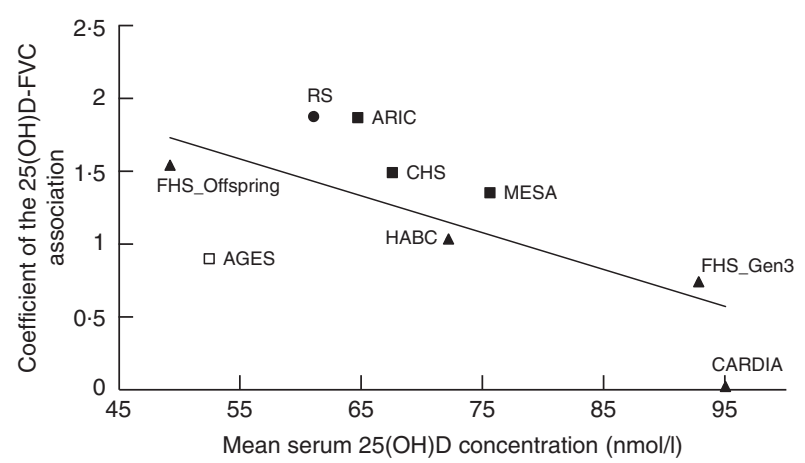

Fig. 2. Meta-regression of mean serum 25-hydroxyvitamin $D(25(\mathrm{OH}) \mathrm{D})$ levels against the association estimates of $25(\mathrm{OH}) \mathrm{D}$ with pulmonary function test in nine European ancestry cohorts in the Cohorts for Heart and Aging Research in Genomic Epidemiology Consortium. (a) Forced expiratory volume in the 1st second $\left(F V_{1}\right)$ outcome (coefficient unit: $\mathrm{ml}$ per $1 \mathrm{nmol} / \mathrm{l} 25(\mathrm{OH}) \mathrm{D}$ ), and (b) forced vital capacity (FVC) outcome (coefficient unit: ml per $1 \mathrm{nmol} / \mathrm{l} 25(\mathrm{OH}) \mathrm{D}$ ). The modifier is mean serum 25(OH)D level of each nine cohorts. A linear regression line is present for each sub-figure, with a meta-regression $P$ value of 0.0006 for the FEV 1 outcome, and 0.005 for the FVC outcome. The figure also shows the measurement method for the serum $25(\mathrm{OH}) \mathrm{D}$ assay (legend shows symbols for each of the four assay methods). $\square$, LC-MS/MS; $\mathbf{\Delta}$, RIA; $\square$, CLIA; Electro-CLIA. LC-MS/MS, liquid chromatography in tandem with mass spectrometry; RIA, radioimmunoassay; CLIA, chemiluminescence immunoassay; MESA, Multi-Ethnic Study of Atherosclerosis; FHS (Offspring), Framingham Heart Study - Offspring Cohort; RS, Rotterdam Study (Netherlands); ARIC, Atherosclerosis Risk in Communities Study; AGES, Age, Gene, Environment, Susceptibility Study - Reykjavik, Iceland; CHS, Cardiovascular Health Study; HABC, Health, Aging, and Body Composition Study; CARDIA, Coronary Artery Risk Development in Young Adults Study; FHS (Gen3), Framingham Heart Study - Generation 3 Cohort.

biological mechanisms may support a causal association between low 25(OH)D levels and worse pulmonary function. First, lung tissue cells can locally convert $25(\mathrm{OH}) \mathrm{D}$ to 1,25 $(\mathrm{OH})_{2} \mathrm{D}^{(36)}$, the active form of vitamin $\mathrm{D}$, which could improve the immune and anti-inflammatory responses in lungs via gene regulation ${ }^{(36-38)}$. If there is not enough circulating $25(\mathrm{OH}) \mathrm{D}$, it is likely that the resolution of inflammation in lungs would be slower, which could have a negative impact on pulmonary function. In addition, $1,25-(\mathrm{OH})_{2} \mathrm{D}$ in lungs, converted locally from $25(\mathrm{OH}) \mathrm{D}$, can regulate the extracellular matrix homeostasis via the ERp60-mediated pathway ${ }^{(39)}$, and this is important for maintenance of lung structure. Furthermore, low vitamin D status could decrease circulating Ca status, which in turn can adversely affect thoracic skeleton mobility and respiratory muscle performance $^{(40,41)}$. (a)

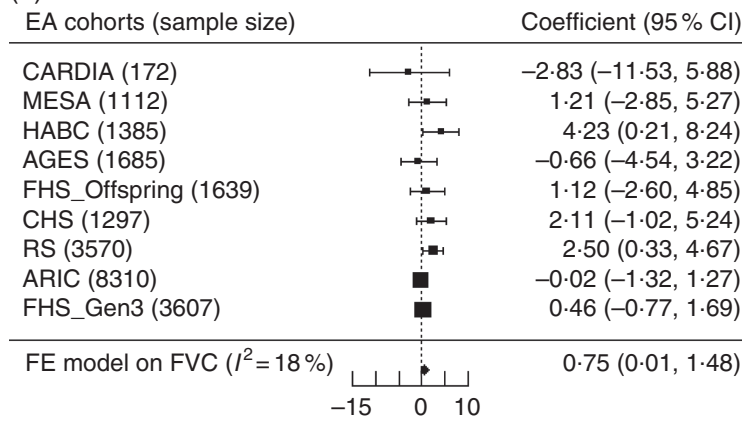

Interaction coefficient of $25(\mathrm{OH}) \mathrm{D}(1 \mathrm{nmol} / \mathrm{l})$ with current smoking

(b)

\begin{tabular}{|c|c|c|}
\hline EA cohorts (sample size) & & Coefficient $(95 \% \mathrm{Cl})$ \\
\hline CARDIA (172) & 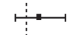 & $2.85(-2.63,8.32)$ \\
\hline FHS_Offspring (1639) & -1 & $-0.37(-3.16,2 \cdot 43)$ \\
\hline $\operatorname{MESA}(1112)$ & -1 & $0.29(-1.95,2.54)$ \\
\hline AGES (1685) & -1 & $0.44(-1.80,2.68)$ \\
\hline HABC (1385) & $t_{1}$ & $1.30(-0.86,3.45)$ \\
\hline CHS (1297) & $=-1$ & $3.10(0.98,5.23)$ \\
\hline RS (3570) & -1 & $1.89(0.20,3.57)$ \\
\hline ARIC (8310) & - & $-0.03(-1.24,1.18)$ \\
\hline FHS_Gen3 (3607) & $\dot{i}$ & $0.60(-0.37,1.58)$ \\
\hline & 1 & $0.79(0.22,1.36)$ \\
\hline
\end{tabular}

Interaction coefficient of $25(\mathrm{OH}) \mathrm{D}(1 \mathrm{nmol} / \mathrm{l})$ with former smoking

Fig. 3. Forest plots of the interaction meta-analysis of serum 25hydroxyvitamin $D(25(\mathrm{OH}) \mathrm{D})$ and smoking status on forced vital capacity (FVC) in the European ancestry cohorts in the Cohorts for Heart and Aging Research in Genomic Epidemiology Consortium ( $n$ 22777). (a) Current smokers and (b) former smokers. $\beta$ (unit: $\mathrm{ml}$ ) denotes the interaction term coefficient of $25(\mathrm{OH}) \mathrm{D}$ and smoking status on FVC from the fixed effects metaanalysis, per $1 \mathrm{nmol} / /$ increment of $25(\mathrm{OH}) \mathrm{D}$, with its $95 \% \mathrm{Cl}$. Cohorts were ordered from the least to the most precise, and heterogeneity is presented $(\mathcal{F})$. EA, European ancestry; CARDIA, Coronary Artery Risk Development in Young Adults Study; MESA, Multi-Ethnic Study of Atherosclerosis; HABC, Health, Aging, and Body Composition Study; AGES, Age, Gene, Environment, Susceptibility Study - Reykjavik, Iceland; FHS (Offspring), Framingham Heart Study - Offspring Cohort; CHS, Cardiovascular Health Study; RS, Rotterdam Study (Netherlands); ARIC, Atherosclerosis Risk in Communities Study; FHS (Gen3), Framingham Heart Study-Generation 3 Cohort; FE, fixed-effects.

Our findings show that the association of serum $25(\mathrm{OH}) \mathrm{D}$ with $\mathrm{FEV}_{1}$ and $\mathrm{FVC}$ were stronger in magnitude in $\mathrm{AA} v$. EA participants, although the difference by race did not reach statistical significance. The finding may reflect the lower serum 25 $(\mathrm{OH}) \mathrm{D}$ in AA participants, which is consistent with the metaregression finding and with a previous study reporting attenuated associations at higher serum $25(\mathrm{OH}) \mathrm{D}^{(15)}$. Future studies that investigate genetic variation in EA and AA in the context of serum 25(OH)D may help explain the differences.

In EA participants, the positive interaction terms between serum $25(\mathrm{OH}) \mathrm{D}$ and smoking status supported a stronger magnitude of association of serum $25(\mathrm{OH}) \mathrm{D}$ with FVC in current and former smokers than in never smokers, with a consistent, but not statistically significant, difference for $\mathrm{FEV}_{1}$. The interaction finding is consistent with a prior cross-sectional National Health and Nutrition Examination Survey (NHANES) study, which reported a stronger $25(\mathrm{OH}) \mathrm{D}-\mathrm{FEV}_{1}$ association in current and former smokers than in never smokers that was 


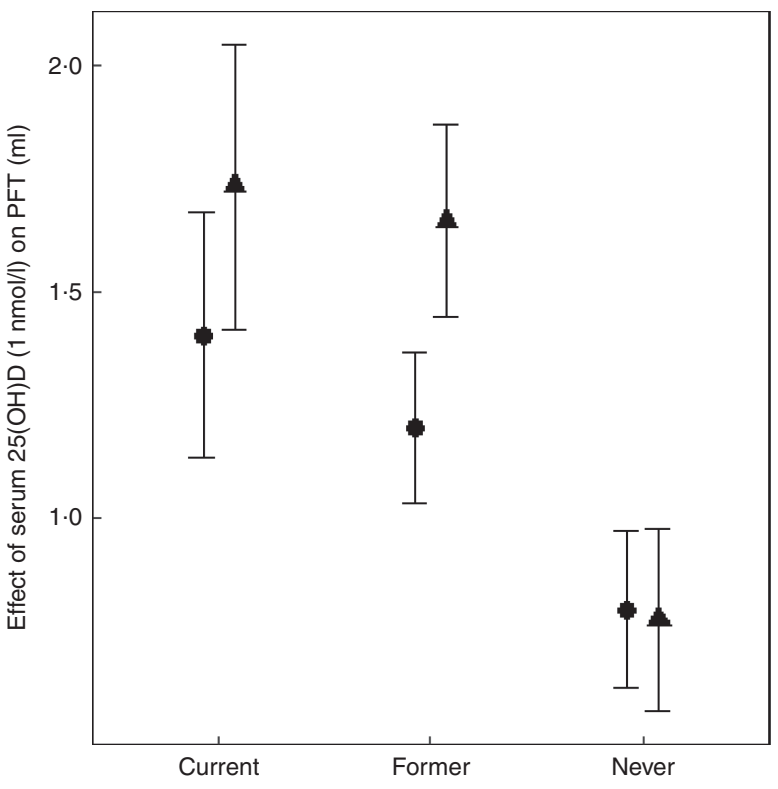

Fig. 4. Meta-analysis of the association of serum 25-hydroxyvitamin D $(25(\mathrm{OH}) \mathrm{D})$ - pulmonary function test outcomes among current, former and never smokers in the European ancestry cohorts in the Cohorts for Heart and Aging Research in Genomic Epidemiology Consortium. Forced expiratory volume in the 1st second $\left(\mathrm{FEV}_{1}, \boldsymbol{O}\right)$ and forced vital capacity $(\mathrm{FVC}, \mathbf{\Delta})$ are presented for each smoking status. $\beta$ (unit: $\mathrm{ml}$ ) denotes that $1 \mathrm{nmol} / /$ higher serum 25(OH)D was associated with a $\beta \mathrm{mL}$ higher $\mathrm{FEV}_{1}$ (or FVC), calculated from an analysis including the interaction of serum $25(\mathrm{OH}) \mathrm{D}$ and smoking status. The error bar represents \pm 1 standard error. We used 22786 European ancestry (EA) participants for the $\mathrm{FEV}_{1}$ outcome and 22777 EA participants for the FVC outcome.

near statistical significance $(P=0 \cdot 06)^{(13)}$. Given smokers have a higher level of oxidative stress and lower pulmonary function than never smokers, partly due to chronic inflammation in lung tissue, the stronger protective association of $25(\mathrm{OH}) \mathrm{D}$ on pulmonary function in smokers suggests a benefit for smokers. To explore this interaction, estimates of the $25(\mathrm{OH}) \mathrm{D}-\mathrm{PFT}$ association were computed within each smoking category. In EA participants, the $25(\mathrm{OH}) \mathrm{D}-\mathrm{FEV}_{1}$ (or FVC) associations were statistically significant in all strata. Generally, in ever smokers of EA, the coefficients for $25(\mathrm{OH}) \mathrm{D}$ were greater for FVC than for $\mathrm{FEV}_{1}$.

Meta-regression provided additional evidence for effect modification by smoking. The proportion of ever smokers was a significant modifier of the association of serum $25(\mathrm{OH}) \mathrm{D}$ with $\mathrm{FEV}_{1}$ and FVC. The higher the proportion of ever smokers, the greater the $25(\mathrm{OH}) \mathrm{D}-\mathrm{PFT}$ association. More specifically, the proportion of former smokers explained the heterogeneity in the 25(OH)D-PFT association across cohorts more fully than the proportion of current smokers; this may be explained by a survival bias in older participants who were current smokers. The meta-regression, based on mean age of the cohorts, showed that cohorts with a higher mean age had a greater association magnitude of $25(\mathrm{OH}) \mathrm{D}$ with $\mathrm{FEV}_{1}$. Given that metaregression analysis uses cohort-level factors (e.g. mean age rather than age of each individual), ecological bias is possible ${ }^{(42)}$. Nevertheless, the age-related meta-regression finding was consistent with a prior NHANES study that showed the association of $25(\mathrm{OH}) \mathrm{D}$ and $\mathrm{FEV}_{1}$ was stronger in people over age 60 compared with younger individuals ${ }^{(13)}$.
Several methodological considerations should be taken into account in interpreting the findings of this study. First, the metaregression showed stronger 25(OH)D-PFT associations in cohorts with lower mean serum $25(\mathrm{OH}) \mathrm{D}$, indicating a nonlinear 25(OH)D-PFT association. This finding is consistent with a prior study in the FHS cohort, which reported a non-linear association and a stronger $25(\mathrm{OH}) \mathrm{D}-\mathrm{FEV}_{1}$ association in participants at risk of vitamin D deficiency $(<30 \mathrm{nmol} / \mathrm{l})^{(15)}$. Second, serum $25(\mathrm{OH}) \mathrm{D}$ was measured by four different methods across the cohorts. For example, two cohorts with high mean $25(\mathrm{OH}) \mathrm{D}$ (>90 nmol/l) used RIA methods. These same cohorts had a lower magnitude estimate of the $25(\mathrm{OH}) \mathrm{D}-\mathrm{PFT}$ association; if the higher mean represents the 'truth' (and is not caused by measurement error in the RIA assay), then the lower 25(OH)DPFT association may be primarily driven by the vitamin $\mathrm{D}$ distribution and not by the RIA method. Whether the assay method itself directly influences the estimate of the 25(OH)D-PFT association requires further data. Third, in this cross-sectional meta-analysis, minor differences were found in the time separation between the measurement of serum 25(OH)D and pulmonary function, but the meta-regression test for heterogeneity confirmed that time separation between measurements did not affect the 25(OH)D-PFT associations. Indeed, past studies with longitudinal measurements of serum 25(OH)D reported a high correlation of $25(\mathrm{OH}) \mathrm{D}$ measurements over a long period of time, with a correlation coefficient of 0.7 for measurements separated by 1 year, 0.5 for measurements separated by 5 years ${ }^{(43)}$, and $0.42-0.52$ for measurements separated by 14 years $^{(44)}$, which supports the use of a single 25 (OH)D measurement to represent usual level. Fourth, residual confounding was unlikely given the consistent results across multiple cohorts in various settings. Weight was adjusted for the FVC outcome, given that higher weight and adiposity negatively affects lung volume (i.e. FVC) ${ }^{(45)}$; weight was not adjusted in the $\mathrm{FEV}_{1}$ models, given $\mathrm{FEV}_{1}$ is a measure of airways obstruction and not physical restriction of lung volume. Physical activity was not adjusted because it is not a confounder in estimating the serum 25(OH)D-PFT association; while physical activity is known to contribute to $\mathrm{O}_{2}$ utilisation in lungs ${ }^{(46)}$, little evidence and no biological rationale exists for a causal association of physical activity with either $\mathrm{FEV}_{1}$ or $\mathrm{FVC}^{(47)}$, which are markers for airways obstruction and lung volume, respectively. Finally, even though three cohorts (AGES, CARDIA, MESA) had the outcome or the exposure only measured in an ancillary study (random subset of the entire cohort), we do not expect selection bias to affect the estimate of the serum vitamin D-PFT association in this meta-analysis; indeed, the association magnitude and direction was consistent across all cohorts, regardless of the proportion of the original cohort contributing to the analysis. Thus, selection bias is expected to be negligible and would likely lead to an underestimated association, given the participants retained in the cohorts are expected to be, on average, healthier than those who were lost to follow-up.

This study meta-analysed the serum 25(OH)D-PFT association across nine cohorts, according to a common pipeline that harmonised the variables and statistical analysis. The sample size comprised 17569 EA participants from the USA; 
5269 EA participants from Iceland and the Netherlands; and 4290 AA participants from the USA, all of whom were 19-95 years old. The sample provided excellent representation of the US population, based on comparisons of demographic factors including sex, height, weight, smoking status and COPD prevalence (about $6 \cdot 1 \%$ ) to national surveys ${ }^{(48-50)}$, which strengthens the external validity of the study's findings.

In summary, using meta-analysis, we estimated a positive association of serum $25(\mathrm{OH}) \mathrm{D}$ with the pulmonary function parameters $\mathrm{FEV}_{1}$ and FVC in both EA and AA participants. Associations varied by smoking status in the EA group, with stronger serum 25(OH)D-PFT associations seen in current and former smokers. The observational design means we cannot infer a causal association, and future studies, such as randomised controlled trials or Mendelian randomisation studies, are needed to further investigate the causality of $25(\mathrm{OH}) \mathrm{D}$ on pulmonary function.

\section{Acknowledgements}

The authors thank Professor James Booth in the Department of Biological Statistics and Computational Biology at Cornell University for providing advice on meta-analysis. The authors thank the staff (Lynn Johnson and Francoise Vermeylen) in Cornell Statistical Consulting Unit for their role in providing advice on methods. The authors also thank Hanfei Xu, PhD student in the research group of Dr Josée Dupuis for his assistance on residual model testing in the Framingham Heart Study.

This work was supported by National Institutes of Health (NIH) grant no. R21 HL125574 funded by the National Heart, Lung, and Blood Institute (NHLBI) and the NIH Office of Dietary Supplements (ODS) (multiple principal investigators (MPIs): D. B. H. and P. A. C.). The corresponding author (P. A. C.) had full access to the data for the meta-analysis, and had final responsibility for the decision to submit for publication. No funding source had any role in the analysis of the data, the writing of the manuscript or the decision to submit it. This work was also supported in part by R01HL077612 (PI: R. G. B.) and by the Intramural Research Program of the NIH, National Institute of Environmental Health Sciences (ZO1 ES043012, PI: S. J. L.). S. J. L. is supported by the Intramural Research Program of NIH, National Institute of Environmental Health Sciences. Infrastructure for the CHARGE Consortium is supported in part by the NHLBI grant R01HL105756. The Age, Gene, Environment, Susceptibility (AGES)-Reykjavik Study has been funded by NIH contracts N01-AG-1-2100 and 271201200022C, the National Institute on Aging (NIA) Intramural Research Program, Hjartavernd (the Icelandic Heart Association) and the Althingi (the Icelandic Parliament). The study is approved by the Icelandic National Bioethics Committee, VSN: 00-063. The researchers are indebted to the participants for their willingness to participate in the study. The Atherosclerosis Risk in Communities Study is carried out as a collaborative study supported by NHLBI contracts HHSN268201100005C, HHSN2 68201100006C, HHSN268201100007C, HHSN268201100008C, HHSN268201100009C, HHSN268201100010C, HHSN2682011 00011C and HHSN268201100012C. 25(OH)D measurements were conducted with the support of R01 HL103706 from the NHLBI and R01 HL103706-S1 from the NIH ODS. The authors thank the staff and participants of the ARIC study for their important contributions. This Cardiovascular Health Study (CHS) research was supported by NHLBI contracts HHSN26 8201200036C, HHSN268200800007C, N01HC55222, N01HC8 5079, N01HC85080, N01HC85081, N01HC85082, N01HC85083, N01HC85086 and NHLBI grants U01HL080295, R01HL085251, R01HL087652, R01HL105756, R01HL103612, R01HL120393 and R01HL130114 with additional contribution from the National Institute of Neurological Disorders and Stroke. Additional support was provided through R01AG023629 from NIA. A full list of principal CHS investigators and institutions can be found at CHS-NHLBI.org. The content is solely the responsibility of the authors and does not necessarily represent the official views of the National Institutes of Health. Vitamin D measurements were made possible by NHLBI (R01HL084443-01A2). This work in Framingham Heart Study was supported by NHLBI's Framingham Heart Study contract (N01-HC-25195 and HHSN26 8201500001I). Vitamin D measurements in the Framingham study were made possible by NIA (R01 AG14759 to S. L. B.). The Health Aging and Body Composition cohort study was supported by NIA contracts N01AG62101, N01AG2103 and N01AG62106, NIA grant R01-AG028050, National Institute of Nursing Research grant R01-NR012459, and in part by the Intramural Research Program of the NIA, NIH. This research was further supported by RC1AG035835 and the serum vitamin D assays were supported by R01AG029364. The Multi-Ethnic Study of Atherosclerosis (MESA) study is conducted and supported by NHLBI in collaboration with MESA investigators. Support for MESA is provided by contracts HHSN26820 1500003I, N01-HC-95159, N01-HC-95160, N01-HC-95161, N01HC-95162, N01-HC-95163, N01-HC-95164, N01-HC-95165, N01HC-95166, N01-HC-95167, N01-HC-95168, and N01-HC-95169 from NHLBI, UL1-TR-000040, UL1-TR-001079 and UL1TR-001881 from the National Center for Research Resources and DK063491 from the National Institute of Diabetes and Digestive and Kidney Diseases. The MESA Lung study was supported by grants R01 HL077612, RC1 HL100543 and R01 HL093081 from NHLBI. Support for the Mineral Metabolite dataset was provided by grant HL096875. The Rotterdam Study is funded by Erasmus Medical Center and Erasmus University, Rotterdam, the Netherlands; the Organization for the Health Research and Development (ZonMw); the Research Institute for Diseases in the Elderly; the Dutch Ministry of Education, Culture, and Science; the Dutch Ministry for Health, Welfare, and Sports; the European Commission (DG XII), and the Municipality of Rotterdam. L. L. was a postdoctoral fellow of the Research Foundation-Flanders (FWO) in Brussels, Belgium. Part of this work was supported by a FWO-grant G035014N. DSM Nutritional Products AG, Kaiseraugst, Switzerland, sponsored the Vitamin D serum analyses. The authors are grateful to the study participants, the staff from the Rotterdam Study, and the participating general practitioners and pharmacists. The Coronary Artery Risk Development in Young Adults Study (CARDIA) is supported by contracts HHSN268201300025C, HHSN268201300026C, HHSN268201300027C, HHSN268201300 028C, HHSN268201300029C and HHSN268200900041C from 
the NHLBI, the Intramural Research Program of the NIA and an intra-agency agreement between NIA and NHLBI (AG0005).

P. A. C., D. B. H. and J. X. conceived and designed the study. R. G. B., J. L., J. D., S. A. G., L. L., S. J. L., K. E. N., A. V. S., B. M. P. and L. M. S. provided the data and supervised the data analysis in each cohort. J. X., T. M. B., R. R. R., A. V. S., A. W. M., F. S., N. T. and X. Z. analysed data within each cohort. J. X., P. A. C. and D. B. H. meta-analysed and interpreted the data, co-wrote and edited the first draft of the manuscript and had primary responsibility for final content. All authors provided data, analytic support and/or study design suggestions at all stages, critically reviewed the manuscript and read and approved the final version.

Dr B. M. P. serves on the DSMB of a clinical trial funded by the manufacturer (Zoll LifeCor) and on the Steering Committee of the Yale Open Data Access Project funded by Johnson \& Johnson. All other authors have no conflicts of interest. There is no commercial support or financial interest from the tobacco industry for the research presented.

The study sponsors were not involved in study design, data collection, data analysis, data interpretation, report writing or decisions to submit the paper for publication. P. A. C. and D. B. H. had final responsibility for the decision to submit for publication.

\section{Supplementary material}

For supplementary material/s referred to in this article, please visit https://doi.org/10.1017/S0007114518002180

\section{References}

1. Minino AM, Murphy SL, Xu J, et al. (2011) Deaths: final data for 2008. Natl Vital Stat Rep 59, 1-126.

2. GBD 2016 Causes of Death Collaborators (2017) Global, regional, and national age-sex specific mortality for 264 causes of death, 1980-2016: a systematic analysis for the Global Burden of Disease Study 2016. Lancet 390, 1151-1210.

3. Weiss ST (2010) Lung function and airway diseases. Nat Genet 42, 14-16.

4. Forey BA, Thornton AJ \& Lee PN (2011) Systematic review with meta-analysis of the epidemiological evidence relating smoking to COPD, chronic bronchitis and emphysema. BMC Pulm Med 11, 36.

5. Guerra S, Stern DA, Zhou M, et al. (2013) Combined effects of parental and active smoking on early lung function deficits: a prospective study from birth to age 26 years. Thorax $\mathbf{6 8}$, 1021-1028.

6. Fletcher JM, Basdeo SA, Allen AC, et al. (2012) Therapeutic use of vitamin D and its analogues in autoimmunity. Recent Pat Inflamm Allergy Drug Discov 6, 22-34.

7. Litonjua AA, ebrary Inc. (2012) Vitamin D and the Lung Mechanisms and Disease Associations. New York: Humana Press/Springer. http://proxy.library.cornell.edu/login?url=http:// link.springer.com/openurl?genre=book\&isbn=978-1-61779-887-0

8. Bikle DD, Gee E, Halloran B, et al. (1986) Assessment of the free fraction of 25-hydroxyvitamin $\mathrm{D}$ in serum and its regulation by albumin and the vitamin D-binding protein. $J$ Clin Endocrinol Metab 63, 954-959.

9. Nykjaer A, Dragun D, Walther D, et al. (1999) An endocytic pathway essential for renal uptake and activation of the steroid 25-(OH) vitamin $\mathrm{D}_{3}$. Cell 96, 507-515.
10. Zerwekh JE (2008) Blood biomarkers of vitamin D status. Am J Clin Nutr 87, 1087S-1091S.

11. Nielson CM, Jones KS, Chun RF, et al. (2016) Free 25hydroxyvitamin D: impact of vitamin D binding protein assays on racial-genotypic associations. J Clin Endocrinol Metab 101, 2226-2234.

12. Freedman BI \& Register TC (2012) Effect of race and genetics on vitamin D metabolism, bone and vascular health. Nat Rev Nephrol 8, 459-466.

13. Black PN \& Scragg R (2005) Relationship between serum 25hydroxyvitamin $\mathrm{d}$ and pulmonary function in the third national health and nutrition examination survey. Chest 128, 3792-3798.

14. Choi CJ, Seo M, Choi WS, et al. (2013) Relationship between serum 25-hydroxyvitamin D and lung function among Korean adults in Korea National Health and Nutrition Examination Survey (KNHANES), 2008-2010. J Clin Endocrinol Metab 98, 1703-1710.

15. Hansen JG, Gao W, Dupuis J, et al. (2015) Association of 25hydroxyvitamin $\mathrm{D}$ status and genetic variation in the vitamin $\mathrm{D}$ metabolic pathway with FEV1 in the Framingham Heart Study. Respir Res 16, 81.

16. Afzal S, Lange P, Bojesen SE, et al. (2014) Plasma 25hydroxyvitamin $\mathrm{D}$, lung function and risk of chronic obstructive pulmonary disease. Thorax 69, 24-31.

17. Berry DJ, Hesketh K, Power C, et al. (2011) Vitamin D status has a linear association with seasonal infections and lung function in British adults. Br J Nutr 106, 1433-1440.

18. Thuesen BH, Skaaby T, Husemoen LL, et al. (2015) The association of serum $25-\mathrm{OH}$ vitamin $\mathrm{D}$ with atopy, asthma, and lung function in a prospective study of Danish adults. Clin Exp Allergy 45, 265-272.

19. Tolppanen AM, Williams D, Henderson J, et al. (2011) Serum 25-hydroxy-vitamin D and ionised calcium in relation to lung function and allergen skin tests. Eur J Clin Nutr 65 , 493-500.

20. Shaheen SO, Jameson KA, Robinson SM, et al. (2011) Relationship of vitamin D status to adult lung function and COPD. Thorax 66, 692-698.

21. Niruban SJ, Alagiakrishnan K, Beach J, et al. (2015) Association between vitamin $\mathrm{D}$ and respiratory outcomes in Canadian adolescents and adults. $J$ Asthma 52, 653-661.

22. Tolppanen AM, Sayers A, Granell R, et al. (2013) Prospective association of 25-hydroxyvitamin $\mathrm{D}_{3}$ and $\mathrm{D}_{2}$ with childhood lung function, asthma, wheezing, and flexural dermatitis. Epidemiology 24, 310-319.

23. Lange NE, Sparrow D, Vokonas P, et al. (2012) Vitamin D deficiency, smoking, and lung function in the Normative Aging Study. Am J Respir Crit Care Med 186, 616-621.

24. Khan S, Mai XM \& Chen Y (2013) Plasma 25-hydroxyvitamin D associated with pulmonary function in Canadian adults with excess adiposity. Am J Clin Nutr 98, 174-179.

25. O'Neal JD (2015) Vitamin D supplementation regimens for HIV-infected patients: a historical chart review. Scholar Archive, paper 3661.

26. Mannino DM, Diaz-Guzman E \& Buist S (2011) Pre- and postbronchodilator lung function as predictors of mortality in the Lung Health Study. Respir Res 12, 136.

27. Phinney KW (2008) Development of a standard reference material for vitamin D in serum. Am J Clin Nutr 88, 511S-512S.

28. Lederer DJ, Enright PL, Kawut SM, et al. (2009) Cigarette smoking is associated with subclinical parenchymal lung disease: the Multi-Ethnic Study of Atherosclerosis (MESA)lung study. Am J Respir Crit Care Med 180, 407-414.

29. Fujiyoshi A, Polgreen LE, Hurley DL, et al. (2013) A crosssectional association between bone mineral density and parathyroid hormone and other biomarkers in community- 
dwelling young adults: the CARDIA study. J Clin Endocrinol Metab 98, 4038-4046.

30. Harris TB, Launer LJ, Eiriksdottir G, et al. (2007) Age, Gene/ Environment Susceptibility-Reykjavik Study: multidisciplinary applied phenomics. Am J Epidemiol 165, 1076-1087.

31. Runarsdottir SB, Gudmundsson G, Aspelund T, et al. (2013) Prevalence of airflow obstruction in nonsmoking older individuals using different spirometric criteria: the AGES Reykjavik Study. COPD 10, 493-499.

32. Morris TP, Fisher DJ, Kenward MG, et al. (2018) Meta-analysis of Gaussian individual patient data: two-stage or not twostage? Stat Med 37, 1419-1438.

33. Higgins JP, Thompson SG, Deeks JJ, et al. (2003) Measuring inconsistency in meta-analyses. BMJ 327, 557-560.

34. Borenstein M, Wiley InterScience (Online service) (2009) Introduction to Meta-analysis. Chichester: John Wiley \& Sons. http://encompass.library.cornell.edu/cgi-bin/checkIP.cgi?access= gateway_standard\%26url=http://onlinelibrary.wiley.com/book/ $10.1002 / 9780470743386$

35. Mirabelli MC, Preisser JS, Loehr LR, et al. (2016) Lung function decline over 25 years of follow-up among black and white adults in the ARIC study cohort. Respir Med 113, 57-64.

36. Hansdottir S, Monick MM, Hinde SL, et al. (2008) Respiratory epithelial cells convert inactive vitamin D to its active form: potential effects on host defense. J Immunol 181, 7090-7099.

37. Colotta F, Jansson B \& Bonelli F (2017) Modulation of inflammatory and immune responses by vitamin D. J Autoimmun 85, 78-97.

38. Dimeloe S, Richards DF, Urry ZL, et al. (2012) 1alpha,25dihydroxyvitamin $\mathrm{D}_{3}$ promotes $\mathrm{CD} 200$ expression by human peripheral and airway-resident T cells. Thorax 67, 574-581.

39. Boyan BD, Wong KL, Fang M, et al. (2007) 1alpha, 25(OH) $2 \mathrm{D}_{3}$ is an autocrine regulator of extracellular matrix turnover and growth factor release via ERp60 activated matrix vesicle metalloproteinases. J Steroid Biochem Mol Biol 103, $467-472$.
40. Herr C, Greulich T, Koczulla RA, et al. (2011) The role of vitamin $\mathrm{D}$ in pulmonary disease: COPD, asthma, infection, and cancer. Respir Res 12, 31.

41. Schlaich C, Minne HW, Bruckner T, et al. (1998) Reduced pulmonary function in patients with spinal osteoporotic fractures. Osteoporos Int 8, 261-267.

42. Thompson SG \& Higgins JP (2002) How should metaregression analyses be undertaken and interpreted? Stat Med 21, 1559-1573.

43. Hofmann JN, Yu K, Horst RL, et al. (2010) Long-term variation in serum 25-hydroxyvitamin D concentration among participants in the Prostate, Lung, Colorectal, and Ovarian Cancer Screening Trial. Cancer Epidemiol Biomarkers Prev 19, 927-931.

44. Jorde R, Sneve M, Hutchinson M, et al. (2010) Tracking of serum 25-hydroxyvitamin $\mathrm{D}$ levels during 14 years in a population-based study and during 12 months in an intervention study. Am J Epidemiol 171, 903-908.

45. Amara CE, Koval JJ, Paterson DH, et al. (2001) Lung function in older humans: the contribution of body composition, physical activity and smoking. Ann Hum Biol 28, 522-536.

46. Burri PH, Gehr P, Muller K, et al. (1976) Adaptation of the growing lung to increased VO2. I. IDPN as inducer of hyperactivity. Respir Physiol 28, 129-140.

47. Cheng YJ, Macera CA, Addy CL, et al. (2003) Effects of physical activity on exercise tests and respiratory function. $\mathrm{Br} \mathrm{J}$ Sports Med 37, 521-528.

48. Jamal A, Homa DM, O'Connor E, et al. (2015) Current cigarette smoking among adults - United States, 2005-2014. MMWR Morb Mortal Wkly Rep 64, 1233-1240.

49. Fryar CD, Gu Q \& Ogden CL (2012) Anthropometric reference data for children and adults: United States, 2007-2010. Vital Health Stat 11, 1-48.

50. Ward BW, Nugent CN, Blumberg SJ, et al. (2017) Measuring the prevalence of diagnosed chronic obstructive pulmonary disease in the United States using Data from the 2012-2014 National Health Interview Survey. Public Health Rep 132, 149-156. 